\title{
Sound, Media Art, and the Metaverse
}

\author{
Vibeke Sorensen \\ School of Art, Design, and Media, Nanyang Technological University \\ vsorensen@ntu.edu.sg
}

\begin{abstract}
The author discusses the fundamental role of sound in global cultures, introduces related perceptual and scientific phenomena such as synesthesia, and provides an overview of their relationship to the development of transmodal multimedia art and design forms emerging at the intersection of physical and digital media, including wireless technologies, social networks, and ubiquitous computing. The article is an edited version of the introductory address given at the opening event of Si15 Soundislands Festival, on Wednesday 19 August 2015, at the Arts House, Singapore.
\end{abstract}

Keywords: synaesthesia, neuroscience, visual music, animation, multimedia, wearable technologies

Sound fills space and our hearts and minds. It expresses our deepest feelings and emotions, and is often used for important rituals and to set the mood for special occasions. It has been refined for use in theatre, films, multimedia and experience design for museums, shopping malls, restaurants, homes, and even our bodies with wearable technologies. It is immersive and migratory, extending into the air, literally and metaphorically. It is like architecture, or liquid architecture, as we are inside it. It is spatial and temporal, like walking through a building or swimming. And sound is mathematical, a physical phenomenon that we can measure in frequency, amplitude, and so forth. Today with malleable digital media, when all measurable phenomena can be digitized, sound can be translated into and across a wide range of sense-based media forms blending boundaries. Sound can be visualized and images become sounds, temperature become color, $\mathrm{CO}_{2}$ pitch (as in the case of my own projects with 'singing' plants), and more. The electromagnetic spectrum contains waves and data that our perceptual system did not evolve to perceive, but now we literally can listen to. New technologies give us access to realities we did not know existed, and more than that, the ability to perceive in new ways other realities so as to gain deeper understanding of, and empathy for others. For me, this is the most important outcome. Our music and art can bring heart to the mind.

One important element is synaesthesia, a well-known phenomenon wherein an impression in one sensory modality arouses impressions in another. It has been studied both in the sciences, such as psychology and neuroscience, and in art and design. It has been explored creatively by artists for centuries, including the celebrated Russian composer Alexander Scriabin (1871 - 1915) who scored for colored lights in his 1910 musical masterpiece, Prometheus: The Poem of Fire.

With technologies that were invented to converge the senses, such as sound-film projection and computer animation ${ }^{1}$, whole new

\footnotetext{
${ }^{1}$ John Whitney, Sr (1917-1995) widely known as the "father of computer graphics" was an American experimental animator and composer whose vision of unifying music and moving images through the common foundation of wave theory led him to the first use of computers for moving images in the 1950s. See Whitney, John (1980). "Digital Harmony: On the Complementarity of Music and Visual Art", McGraw-Hill.
} 
genres of experimental art were pioneered that led to huge new industries. This includes Oskar Fischinger (1900-1967), who gave 'visval music' its name and developed Disney's greatest masterpiece Fantasia (1940). Visual music pioneers led the way to "light shows" in the 1960s, and MTV in the 1980s. Today almost everyone has a music app with graphics running on their laptops as screen savers.

Sound technology in particular, including mechanical and electrical, often integrated multiple senses. The ideas informing it go back to Pythagoras of Samos (Greece, c. $570-$ c. $495 \mathrm{BC}$ ) who described mathematical relationships between musical pitch and geometry, and span millennia that followed and include Sir Isaac Newton $(1643-1727)$ who theorized correspondences between colors in light and notes in a musical scale. There is also the French mathematician Father Louis-Bertrand Castel (1688 - 1757) who in 1725 famously created the "ocular harpsichord," a color organ made of candles, colored glass, and moving curtains that whenever a key was pressed opened to reveal a colored light behind it. And there is Thomas Edison (1847 - 1931) who invented the phonograph and the movie camera. We can add many $20^{\text {th }}$ century artists, composers, and researchers such as Max Matthews $(1926-2011)$ who worked at Bell Laboratories (1950s - 1980s), IRCAM (1970s), and Stanford University (1985 - 2011). There have been other great researchers in academia, industry and companies like Yamaha in Japan, including people participating in this very festival.

Science, music, and art have been having an inspired conversation for thousands of years, striving to make the invisible visible and the inaudible audible, and provide us with a way of experiencing, making sense of, and exploring the unknown: that which we know exists but that we still do not understand. Artists, composers, and technologists are working at the edge of understanding by exploring and discovering our universe through the temporal materiality, and increasingly the immaterial rematerialized, of their art forms.

Today, the idea of connecting the senses, realizing the centuries if not millennia old dream of unifying the arts, or "gesamtkunstwerk" ${ }^{\prime 2}$, sits at the foundation of media art. Sound is at the centre. Sound and music, as in opera, have always incorporated space, time, performance, and multiple modalities. Today, through the powerful vehicle of data and information systems, the potential is vastly expanded. It is extended further with the blending of scientific knowledge of how the brain works, or neuroscience, with our distributed, wireless, networked, and pervasive technologies that permeate our increasingly connected digital metaverse.

Signals from the brain and body activate nerve connections that elicit feelings and emotions, patterns of neural pathways that give rise to the formation and playback of memories. These patterns are constantly reconfiguring themselves as we move, creating new pathways and patterns that with each new experience mix memory and sensation into an ongoing stream of consciousness, and a continuously updated narrative that we engage and contemplate. We are in a continual process of creation, always predicting and inventing the future based on experience of the past and present, so as to be able to move and survive in a constantly changing world that surrounds us. How the brain creates a mental model of the world through sensory impressions that somehow conform to it, is still not understood. It is called the "binding problem."

Again, it is artists and composers who are shedding light on this problem through their creative work and artistic research with media. They are asking questions about representation and whether or not the models are "correct," how to work imaginatively and sensitively with them, and what those models could do to help us understand and anticipate the complex changing environment. Sound, computer music, and media art are merging with environmental and social science as an emerging form of bio-social-art. They are shedding light

\footnotetext{
2 "Gesamtkunstwerk" is German for "total work of art," a term first coined by philosopher K. F. E. Trahndorff in 1827 and subsequently used by opera composer Richard Wagner in two essays written in 1849: "Art and Revolution", and "The Artwork of the Future", which further disseminated the term.
} 
on how groups of people and other living things such as plants and animals communicate with each other and their environment, how they relate, and even how they cooperate to survive and evolve. ${ }^{3}$

Composers, sound and media artists have catalyzed the development of new technologies for communication because we exist in time and, as speakers in this festival including Si15 Soundislands Festival Chair PerMagnus Lindborg, Nora Turoman, Suzy Styles, Bani Haykal, and Daniel Belton reflect upon in their presentations, because our languages are temporal. In fact "artists-in-labs" is a proven strategy for technological innovation. Bell Laboratories, mentioned earlier, brought composers and artists into their sound research labs starting more than 50 years ago with the expectation that in creating their own pieces they would accelerate the development of tele-communications technologies. This same Research and Development (R\&D) strategy was widely adopted in the 1970s - 2000s in the computer graphics and multimedia industry including NASA, Xerox PARC, Microsoft, and many others.

Language exists in time and reflects upon our existence individually and collectively. All of our senses influence each other and shape our thoughts. Narrative is the meaning we give to sequential sensory experience, the stored impressions that are the patterns of neural connections that we re-member to create that exquisite tapestry that is our on-going story. Aroma in particular stimulates memories and enhances perception in other sensory domains. This is being explored scientifically and used creatively in multimodal art. We are just now starting to understand how it works, how to develop it to improve life, and provide heightened experiences of greater sensitivity, enjoyment, awe, and hopefully also compassion.

\footnotetext{
3 The Second International Congress on Animal Computer Interaction was held in Johor, Malaysia in November 2015 as part of Advances in Computer Entertainment (ACE) and in association with ACM SIGGRAPH and ACM SIGCHI. See URL http://animalcomputerinteraction.org/index.html
}

We know this is possible from our daily experience of life, including the delicious food we eat and the exciting relationships being discovered between taste and sound, which Si15 Keynote Speaker Charles Spence is exploring as the head of the Crossmodal Research Group at the University of Oxford. We also know it from our experience of exquisite rainbow colors observed in the refracted light of the sun, in ethereal textures that swirl around us in high dynamic range spatial sound, and in sumptuous physical and dreamlike virtual materials that we touch and play with esthetic refinement. We express our mood in food, music and clothing every day. With wearable technologies, we can correlate our feelings and expressions with data from our bodies. We can 'tune' our bodies to our internal and external environment through sound and music using sensors and biofeedback. This can be used for medical purposes, letting us know that when we feel good, it really is good. Evolutionary biologists tell us that we "like" certain kinds of images (and presumably also sounds) because in the past those things they represent helped us to survive. A template seems to be stored in our collective DNA. My view, then, is that we are moving increasingly from "natural" selection to "esthetic" selection.

There are so many exciting new works of art for us to experience, contemplate, and learn from that exist in time and have at their core, sound and music.

From an exploration of that which has come before (i.e. history) while embracing a fundamental respect for life, and the individual and the social in an approach that emphasizes the humanization of technology and a conception of networks not just as technological but "e-cological" (a network not just of things but of living things), to the mysteriously embodied and sentient environment (a network of the tangible and intangible), we always return to the question of representation and narrative. What are we saying and doing, and how do our ideas and actions affect and reflect the worlds we inhabit? We are in an era of big data, and each of us is unique. And like the "butterfly effect" in a huge orchestra, each person is playing a part. Each sound artist, composer, and multimodal researcher in this festival will 
shed light on their inspired and unique way of feeling and knowing, thinking and telling. We join them in exploring the miracle of the mind and mysteries of the universe. It is a wondrous journey.

We are grateful to all of the artists, and the organisers and hosts, especially the core organising team which includes PerMagnus Lindborg, Suzy Styles, Joyce Beetuan Koh and Stefano Fasciani for creating such an intriguing and relevant event. Special thanks to Andrián Pertout, Seongah Shin, Dirk Stromberg and Daniel Belton. I also want to join the hosts in thanking everyone who provided support. The School of Art, Design and Media (ADM) at Nanyang Technological University Singapore is proud to be a part of this festival. We are in our $10^{\text {th }}$ year in 2015 , which we are celebrating together with $\mathrm{SG}_{50}$. I wish to thank all of our participating faculty and staff, especially the ADM AV, IT and administrative team, for their hard work and contributions. ADM, our iconic heart shaped building is also a kind of island, rising from waves of green to the sky, and joined by vital bridges that you and this festival are making to the entire planet. We unite in the celebration of the flowering of the creative spirit here in Singapore, a vibrant and highly connected global media arts Nation, tonight, throughout this festival, and long into the future.

Thank you for your attention, and I wish everyone an enjoyable Festival. 